\title{
Article
}

\section{One in 10 hospitalised patients have a pressure injury worldwide}

Palmer, Karen, Hill, James Edward and Clegg, Andrew

Available at https://clok.uclan.ac.uk/33438/

Palmer, Karen, Hill, James Edward orcid iconORCID: 0000-0003-1430-6927 and Clegg, Andrew orcid iconORCID: 0000-0001-8938-7819 (2020) One in 10 hospitalised patients have a pressure injury worldwide. Evidence-Based Nursing . ISSN 1367-6539

It is advisable to refer to the publisher's version if you intend to cite from the work. http://dx.doi.org/10.1136/ebnurs-2020-103276

For more information about UCLan's research in this area go to http://www.uclan.ac.uk/researchgroups/ and search for <name of research Group>.

For information about Research generally at UCLan please go to http://www.uclan.ac.uk/research/

All outputs in CLoK are protected by Intellectual Property Rights law, including Copyright law. Copyright, IPR and Moral Rights for the works on this site are retained by the individual authors and/or other copyright owners. Terms and conditions for use of this material are defined in the policies page.

\section{CLoK}

Central Lancashire online Knowledge www.clok.uclan.ac.uk

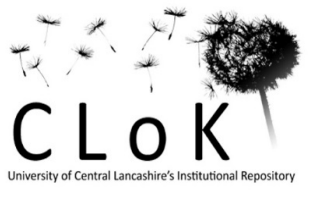




\section{Category:}

\section{Study type:}

Author's declarative title: One in ten hospitalised patients have a pressure injury worldwide.

\section{Commentary on:}

\section{Commentary Implications for practice and research}

- The estimated worldwide pressure injury prevalence is $12.8 \%$ in hospitalised adults.

- Hospitals should continue to see pressure injuries as a priority.

- Future pressure injury prevalence studies should ensure appropriate sampling methods and training for data collectors.

\section{Context}

A pressure injury $(\mathrm{PI})$ or pressure ulcer is a localised skin and/or tissue damage that results from sustained pressure and/or sheer (1). Pls have significant clinical and economic impact on the patient and healthcare systems with the potential to prolong hospitalisation and increase both morbidity and mortality (2). Despite extensive prevention programmes, evidence suggests that the prevalence of PIs and the economic burden continues to rise (3). This systematic review and meta-analysis aim to provide an up-to-date, pooled estimate of pressure injury prevalence in hospitalised adult patients worldwide (4).

\section{Methods}

This protocol registered systematic review undertook a comprehensive literature search of multiple databases. A restricted date range of 2008 to December 2018 was used due to concerns of historical inconsistencies defining what is a pressure injury. Only observational, cross-sectional or longitudinal studies reporting the prevalence and/or incidents of all stages of pressure injuries for the whole hospital for adults were included. Studies were excluded if they focused on a specific type of pressure injuries. Abstract title and full paper screening were undertaken by two independent reviewers (not reported in full paper, only described in protocol). Data extraction was undertaken by a single reviewer and verified by a second reviewer. A robust assessment of bias was undertaken using the Hoy's risk of bias tool. An appropriate meta-analysis was undertaken using both fixed and random effects models depending on level of heterogeneity. 


\section{Findings}

The overall risk of bias for the majority of included studies was deemed to be of low to moderate risk. The findings highlighted the substantial burden of pressure injuries in hospitalised adults with a pooled prevalence estimate of $1,366,848$ patients was $12.8 \%(95 \% \mathrm{Cl} 11.8-13.9 \%)$ and the majority of pressure injuries being hospital acquired. With a pooled hospital-acquired pressure injuries rate of $1,893,593$ which is $8.4 \%(95 \% \mathrm{Cl} 7.6-9.3 \%)$ and a pooled incidence rate of 681,885 patients was 5.4 per 10,000 patient-days (95\% Cl 3.4-7.8). There was substantial heterogeneity for both pooled estimates which were mainly explained by year of data collection, mean age and gender. The majority of pressure injuries were Stage I (43.5\%) and Stage II (28.0\%) and located on the sacrum, heels and hips respectively.

\section{Commentary}

This review enhances the findings of two previous systematic reviews which identified the incidence and prevalence of pressure injuries in acute care settings by considering the staging of the injury and its anatomical location(s). For the first time, a meta-analysis was undertaken to address the questions of interest.

Using the Joanna Briggs Institute Critical Appraisal tool for systematic reviews 11 out of the 11 criteria were judged to be satisfactory for this review. Thus, it was deemed that this systematic review provides an accurate and comprehensive summary of the results of the available studies that address the question of interest.

Based on the findings of this review, hospitals should continue to see pressure injuries as a priority with a focus on in-hospital preventative measures, continued surveillance and improvement programmes. It is important as well as these improvement strategies, that additional human and other resources are prioritised to treat pressure injuries, as about one in 10 in-hospital patients will have a pressure injury. One of the key focuses of treatment should be on treating Stage I pressure injuries as they make up a high proportion of all pressure injuries reported and are a known risk factor for higher stages of pressure injury development.

Future research on prevalence and incidence of pressure injuries should ensure that appropriate sampling methods are used for the target population with a clear description of the targeting frame. Furthermore, future studies should ensure that there is clear reporting of response rates and appropriate strategies in place to help to limit non-response rates. All assessments should be carried out by appropriately trained individuals, and where appropriate inter-rater reliability results should be reported. 


\section{References}

1. NHS. Pressure ulcers: revised definition and measurement NHS Improvement; 2018. Available from:

https://improvement.nhs.uk/documents/2932/NSTPP_summary_recommendations 2.pdf

2. Ferris A, Price A, Harding K. Pressure ulcers in patients receiving palliative care: A systematic review. Palliative medicine. 2019;33(7):770-82.

3. Guest JF, Vowden K, Vowden P. The health economic burden that acute and chronic wounds impose on an average clinical commissioning group/health board in the UK. Journal of wound care. 2017;26(6):292-303.

4. $\quad$ Li Z, Lin F, Thalib L, Chaboyer W. Global prevalence and incidence of pressure injuries in hospitalised adult patients: A systematic review and metaanalysis. International journal of nursing studies. 2020;105:103546.

\section{Commentator details}

Name: James Edward Hill

Affiliation: University of Central Lancashire

Correspondence address:

University of Central Lancashire,

Preston, Lancashire

PR1 2HE

Email: Jehill1@uclan.ac.uk

\section{Competing interests}

I have no conflicts of interest with any aspect of this publication.

Acknowledgements: This report is independent research funded by the National Institute for Health Research Applied Research Collaboration North West Coast (ARC NWC). The views expressed in this publication are those of the author(s) and not necessarily those of the National Institute for Health Research or the Department of Health and Social Care. 